\title{
Hypocholestorolemic effects of probiotic yoghurts
}

\author{
Sadeq Hasan Al-Sheraji ${ }^{*}, \dagger^{1}$, Amin Ismail ${ }^{2}$, Azrina Azlan ${ }^{3}$ \\ ${ }^{1}$ Department of Nutrition, Universiti Putra Malaysia and Dietetics, Faculty of Medicine and Health Sciences, Laboratory of Halal \\ Science Research, Halal Products Research Institutes, \\ ${ }^{2}$ Department of Nutrition and Dietetics, Faculty of Medicine and Health Sciences, Universiti Putra Malaysia, 43400 UPM Serdang, \\ Selangor, Malaysia.,Department of Food Science, Faculty of Agriculture, Ibb University, Ibb, Yemen. \\ ${ }^{3}$ Department of Nutrition,Laboratory of Halal Science Research, Halal Products Research Institutes, Universiti Putra Malaysia, 43400 \\ UPM Serdang, Selangor, Malaysia and Dietetics, Faculty of Medicine and Health Sciences, Universiti Putra Malaysia, 43400 UPM \\ Serdang, Selangor, Malaysia.
}

DOI: https://doi.org/10.15520/ijmhs.v9i2.2446

Accepted 08 Feb 2019; Received 19 Dec 2018; Publish Online 28 Feb 2019

\section{Reviewed By: Dr. \\ Daniel V. Department: Medical}

\begin{abstract}
Cardiovascular disease is one of the most important reasons of death in the world and high levels of cholesterol is concerned as an essential risk factor for cardiovascular disease, thus a decrease in serum cholesterol levels can decrease cardiovascular disease. One preventative approaches for reduction of serum cholesterol levels could be caused by consumption of yoghurt containing probiotic bacteria. Probiotics are live microorganisms that provide health benefits when ingestion. There are a big number of probiotics presently utilized and accessible in dairy fermented foods, particularly in yogurts. Lactic acid bacteria represent a varied group of organisms given significant benefits to people, some as usual population of the intestinal area. This review presents relevant information on probiotics such as the definitions and characteristics of probiotic bacteria, their utilization in yogurt preparations, and the claimed benefits of the ingestion of these bacteria, particularly on lowering hypercholesterol.
\end{abstract}

Keywords: Probiotic, Yoghurt, Health, Hypocholestorolemic, Diseases

\section{INTRODUCTION}

The major cause of morbidity and mortality in the world is cardiovascular disease (Alhaj, Kanekanian, Peters, \& Tatham, 2010). Cholesterol is required for certain hormones and vitamin formation, being an essential component of nerve cells and cell membranes. It is one of the danger causes for cardiovascular syndrome as well as other chronic health conditions including arthrosclerosis. However, (Manson, et al., 1992) have shown that $1 \%$ decrease in serum cholesterol level may decrease cardiovascular disease risk to about $3 \%$.

Just as cholesterol is required to maintain body fluids and for other purposes, our dietary food intake may also impact on the composition of our plasma lipids. One intervention measure aimed at maintaining a disease free condition is to manage and/or control triglycerides and blood cholesterol levels in our diet with drug treatment, for example the use of statins (El-Gawad, El-Sayed, Hafez, El-Zeini, \&

* Corresponding author.

$\dagger$ Email: sadek_975(at)yahoo.com.
Saleh, 2005 Pereira \& Gibson, 2002a). Other interventions to reduce blood cholesterol include consumption of foods low in fat and cholesterol (Lora, Morse, Gonzalez-Kruger, \& Driskell, 2007), probiotic bacteria (Schaafsma, Meuling, van Dokkum, \& Bouley, 1998) and dietary fibre (Theuwissen \& Mensink, 2008).

Although a great deal of information has shown that probiotic cultures provide countless health benefits (Gomes da Cruz, Alonso Buriti, Batista de Souza, Fonseca Faria, \& Isay Saad, 2009) such as reducing gastrointestinal disorders, it can also decrease cardiovascular disease risk. Attention in the commercial and scientific fields has been focused on the use of probiotic bacteria as a consequence of the diverse beneficial effects of these bacteria on humans. Probiotics are living microorganisms, which after consumption in certain amounts are capable of promoting the health of the host beyond normal nutrition (Begley, Hill, \& Cormac, 2006). They form a fraction of the components in food products as supplements. Probiotic bacteria have been used for years in food fermentation such as yoghurt which considered the best-known food for probiotics because of its own physico- 
chemical and functional characteristics (do Espírito Santo, Perego, Converti, \& Oliveira, 2011).

Probiotic bacteria are live microorganism that are able to establish themselves in the gastrointestinal tract of the host organism and play pivotal roles in human health support, preventing gastroenteric pathogens (Gaggia, Di Gioia, Baffoni, \& Biavati, 2011 Sánchez, Ruiz, Gueimonde, RuasMadiedo, \& Margolles, 2012) including Campylobacter jejuni, Clostridium difficile, rotavirus and Helicobacter pylori, encouraging overall immune system responsiveness, avoiding intestinal dysfunction and decreasing plasma cholesterol levels (Apostolidis, Kwon, Shinde, Ghaedian, \& Shetty, 2011 Tannock, 1999 Xiao, et al., 2003). It has been reported that consumption of probiotics with dairy products decreases lactose intolerance symptoms in humans (Vrese \& Schrezenmeir, 2008). Probiotic reduced diarrhoea's severity and establishing mucosal cell immune defences in the intestine via specific and non-specific inflammatory reactions (Isolauri \& Salminen, 2008 Johnston, Supina, Ospina, \& Vohra, 2007), they may also impact on lipid and blood glucose levels (Fabian \& Elmadfa, 2007 Parvez, Kim, Lee, \& Kim, 2006).

Research has assessed the effects of probiotic bacteria on serum lipid profiles. Although the mechanism of cholesterol lowering by probiotic bacteria is as yet unobvious, several theories have been suggested to describe the hypocholesterolemic activity of probiotic bacteria and bioactive peptides resulted by their proteolytic activities. Probiotic bacteria could ferment non-digestible polysaccharides in intestinal lumen to result short chain fatty acids (SCFAs) such as propionic acid, which is capable of reduing hepatic cholesterol synthesis. Probiotics are capable of inhibiting intestinal cholesterol absorption by binding bile acids and cholesterol to probiotic bacterial cells, resulting in absorption of cholesterol by probiotic bacteria ((Liong \& Shah, 2005 Pereira \& Gibson, 2002a).

Probiotic bacteria promote cholesterol excretion through the faeces by mean of its electrostatic and hydrophobic interactions with particular peptides. Notwithstanding the beneficial health effects of probiotics, they also are capable of meeting targets required for their marketability such as viability and or maintenance of product durability during storage (Al-Sheraji, et al., 2012b). The count levels of probiotic had been recommended to be above $10^{6} \mathrm{cfu} / \mathrm{mL}$ per daily dose (Kurmann \& Robinson, 1991) to avoid washout, and to assure that their benefits will be accrued in a sustained manner (Peres, Peres, Hernández-Mendoza, \& Malcata, 2012). The viability of probiotic organisms in yogurt is influenced by several factors such as the $\mathrm{pH}$ of the medium, culture strain, oxygen content, water activity, storage temperature, starter cultures and interaction between probiotics (Champagne, Raymond, \& Tompkins, 2010 Gilliland, Reilly, Kim, \& Kim, 2002 Heller, 2001 A. Talwalkar \& Kailasapathy, 2004 Walldius \& Jungner, 2004). The present paper provides a background and reviews the present literature relating to probiotics with emphasis on their health benefits. Areas covered include the definition of probiotics, properties of probiotics, viability of probiotics in yogurt during fermentation and storage, effects of probiotics on yogurt properties and their significance for human health, particularly in cardiovascular diseases.

\section{PROPERTIES OF PROBIOTICS:}

The best description of an excellent probiotic and therefore as criteria for the choice of

novel probiotic organisms is as following.

- Species compatibility (preferably probiotic planned for human being have to be taken from human gut, since those taken from diverse sources are normally less effective).

- The capability to stay alive during the gut and get to the intestines in a survival condition.

- Excellent ability to stick on to the intestinal epithelium.

- A short production period so they are able to settle the gut quickly.

- Production of antimicrobial factors that will slow down the increase of pathogens.

- High-quality viability in foods or additives so they have a rational shelf life in products.

- No inherent pathogenicity (present probiotics are commonly known as secure and are non-pathogenic and non-toxin-producing organisms).

1. Antigenotoxic properties (the aptitude to decrease mutation and carcinogenesis, for instance by lowering the production of mutagenic materials by other organisms in the gut)

\section{Common strains of probiotics:}

The mainly frequent species of probiotics are accessible in dairy products and probiotic-fortified foods. Nevertheless, tablets, capsules, powdered and sachets holding the probiotic in lyophilized type are obtainable. Table 1 shows most common strains of probiotics.

Viability of probiotics in yogurt during fermentation:

The viability of probiotic bacteria such as L. acidophilus and Bifidobacterium spp. was found to increase in yogurt during the production process; however, the number of $L$. casei decreased during yogurt production, while $L$. casei E5 and E10 raised around 2 times and B. longum S9 amplified around 3 times but $B$. longum Com did not raise (Gilliland et al., 2002). The viability of 2 bifidobacteria strains, RBL 00079 and RBL 00064, increased during yogurt production, and the growth of L. rhamnosus GG and L. johnsonii La-1 also increased 2 logs when these probiotic microorganisms were added at the same time together with the yogurt culture in cow's milk. In addition, the numbers of 2 bifidobacteria strains, RBL 00079 and RBL 00064 increased notably in cow's milk through yogurt manufacture due to the hydrolysis of milk proteins to yield free 


\section{The Influence Of Specialized Physical Education Program For Students With Health \\ Issues

Table 1. The most common strains of probiotics.

\begin{tabular}{|c|c|c|}
\hline Strain & Brand name & Producer \\
\hline Bifidobacterium animalis DN 173010 & Activia & Danone \\
\hline Bifidobacterium animalis subsp. lactis BB-12 & N.A. & Chr. Hansen \\
\hline Bifidobacterium breve Yakult & Bifiene & Yakult \\
\hline Bifidobacterium infantis 35624 & Align & Procter \& Gamble \\
\hline Bifidobacterium lactis HN019 (DR10) & Howaru Bifido & Danisco \\
\hline Bifidobacterium longum BB536 & N.A. & $\begin{array}{l}\text { Morinaga Milk } \\
\text { Industry }\end{array}$ \\
\hline Escherichia coli M-17 & ProBactrix & BioBalance \\
\hline Escherichia coli Nissle 1917 & Mutaflor & Ardeypharm \\
\hline Lactobacillus acidophilus LA-5 & N.A. & Chr. Hansen \\
\hline Lactobacillus acidophilus NCFM & N.A. & Danisco \\
\hline Lactobacillus casei DN114-001 (Lactobacillus casei Immunitas(s)/Defensis) & Actimel/DanActive & Danone \\
\hline Lactobacillus casei CRL431 & N.A. & Chr. Hansen \\
\hline Lactobacillus casei F19 & Cultura & Arla Foods \\
\hline Lactobacillus casei Shirota & Yakult & Yakult \\
\hline Lactobacillus paracasei St11 (or NCC2461) & Lactobacillus fortis & Nestle \\
\hline Lactobacillus johnsonii La1 and Lactobacillus LC1) & N.A. & Nestle \\
\hline Lactococcus lactis L1A & N.A. & Norrmejerier \\
\hline Lactobacillus plantarum $299 \mathrm{~V}$ & $\begin{array}{l}\text { GoodBelly / ProViva/ } \\
\text { TuZen }\end{array}$ & $\begin{array}{l}\text { NextFoodsProbiFer- } \\
\text { ring }\end{array}$ \\
\hline Lactobacillus reuteriATTC 55730\&Lactobacillus reuteri SD2112 & N.A. & BioGaia Biologics \\
\hline $\begin{array}{l}\text { Lactobacillus rhamnosus ATCC } 53013 \text { (discovered by Gorbach \& } \\
\text { Goldin(=LGG)) }\end{array}$ & Vifit and others & Valio \\
\hline Lactobacillus rhamnosus LB21 & Verum & Norrmejerier \\
\hline Lactobacillus salivarius UCC118 & N.A. & \\
\hline Saccharomyces cerevisiae (boulardii) lyo & DiarSafe and others & $\begin{array}{l}\text { Wren Laboratories } \\
\text { and others }\end{array}$ \\
\hline Lactobacillus rhamnosus GR-1 \&Lactobacillus reuteri RC-14 & $\begin{array}{l}\text { Bion Flore Intime Jarrow } \\
\text { Fem-Dophilus }\end{array}$ & Chr. Hansen \\
\hline $\begin{array}{l}\text { mixture of } 8 \text { strains of Streptococcus thermophilus\& four Lactobacillus } \\
\text { spp\& three Bifidobacterium spp strains }\end{array}$ & VSL\#3 & $\begin{array}{l}\text { Sigma-Tau } \\
\text { Pharmaceuticals, Inc. }\end{array}$ \\
\hline Lactobacillus acidophilus CUL60 \&Bifidobacterium bifidum CUL 20 & N.A. & \\
\hline Lactobacillus helveticus R0052 \&Lactobacillus rhamnosus R0011 & A'Biotica and others & Institut Rosell \\
\hline
\end{tabular}

amino acids by the yogurt culture. In every yogurt having L. rhamnosus, L. johnsoniiLa-1, Bifidobacterium RBL 00079 or Bifidobacterium RBL 00064, the development of the supplementary probiotic was belated for 2 to $4 \mathrm{~h}$ after the begin of the fermentation; that period was necessary to produce adequate amino acids to sustain bacterial growth (Farnworth, et al., 2007).

With regard to the survival of bifidobacteria during yogurt fermentation, there is a high level of $B$. animalis in yogurts containing B. animalis, B. bifidum, B. breve, B. infantis, and $B$. longum when the fermentation was stopped $(4.5 \mathrm{~h})$. Strains of $B$. breve and B. infantis were possibly more sensitive to the fermentation temperature of $44^{\circ} \mathrm{C}$, but this fermentation temperature assisted develop the viability of B. animalis through yogurt production. Bifidobacterium animalis is a strain of animal source, and is stronger and more heat tolerant than other bifidobacteria of human source that has been considered (B. bifidum, B. breve, B. infantis, and B. longum). The temperature of fermentation $\left(44^{\circ} \mathrm{C}\right)$ was unsuitable for those strains. The best temperature for viability of Bifidobacterium spp. of human sources is between 36 and $38^{\circ} \mathrm{C}$, while that for species of animal sources is between 41 and $43^{\circ} \mathrm{C}$. Viability of bifidobacteria does not happen less than $20^{\circ} \mathrm{C}$, and bifidobacteria does not have thermo resistance over $46^{\circ} \mathrm{C}$. As well, B. breve and $B$. infantis might be further responsive to acids formed through fermentation by yogurt bacteria and bifidobacteria than the other strains (Dave \& Shah, 1997 Lamoureux, Roy, \& Gauthier, 2002).

Viability of probiotics in yogurt during storage:

The growth of probiotics in yogurt depends on the $\mathrm{pH}$ of the yoghurt in addition to the species of probiotic (Gilliland et al., 2002). Although no significant $(p>0.05)$ decrease in bifidobacteria and L. acidophilus counts in yogurt occurred during storage (McComas \& Gilliland, 2003 Akshat Talwalkar, Miller, Kailasapathy, \& Nguyen, 2004), but Bifidobacteria counts in yogurt decreased more rapidly after 3 weeks and further decreased after 4 weeks of storage at $4^{\circ} \mathrm{C}$ (Christopher, Padmanabha, \& Venkateswarlu, 2006 Ibrahim \& Carr, 2006). Survival of B. infantis, L.gasseri and $L$. casei in yogurt rose after 10 days but additional storage up to 15 days reduced their survival (Haddadin, Awaisheh, \& Robinson, 2004). S. thermophilus, L. acidophilus and B. Bifidum survived at levels of $>10^{8},>10^{6}$ and $>10^{6}$ $\mathrm{CFU} / \mathrm{mL}$ respectively, after storage of yogurt at $7 \pm 1^{\circ} \mathrm{C}$ for 4 weeks. Nevertheless, reduced viable populations of yogurt bacteria and probiotic cultures (L. acidophilus + bifidobacteria), down to levels of $>10^{7}$ and $>10^{5}$, were noted, respectively, at the end of 30 days of storage (Dave et al., 2002). Other results showed an elevated survival of probiotics, up to a level of $>6 \log \mathrm{CFU} / \mathrm{mL}$ (Maragkoudakis, et al., 2006) or even $>8 \log \mathrm{CFU} / \mathrm{mL}$ (Awaisheh, Haddadin, \& Robinson, 2005) throughout storage of probiotic yogurt. 
The count of probiotic bacteria was sustained more than the recommended therapeutic minimum $\left(10^{7} \mathrm{CFU} / \mathrm{mL}\right)$ during the storage (Krasaekoopt, Bhandari, \& Deeth, 2006).

Effects of probiotics on the viability of yogurt cultures:

B. bifidum elevated the numbers of $S$. thermophilus from 8.37 to $8.42 \log \mathrm{CFU} / \mathrm{mL}$, and L. delbrueckii subsp. bulgaricus from 8.17 to $8.28 \log \mathrm{CFU} / \mathrm{mL}$, while maintaining $B$. bifidum numbers of $8.55 \log \mathrm{CFU} / \mathrm{mL}$. L. acidophilus elevated the counts of $S$. thermophilus to $8.47 \log \mathrm{CFU} / \mathrm{mL}$ and $L$. delbrueckii subsp. bulgaricus to $8.30 \log \mathrm{CFU} / \mathrm{mL}$, while $L$. acidophilus attained numbers of $8.42 \log \mathrm{CFU} / \mathrm{mL}$. Nevertheless, B. bifidum numbers decreased to $8.52 \log \mathrm{CFU} / \mathrm{mL}$ (Yamamah, et al., 2005); there was also an increase in viable populations of $L$. delbrueckii subsp. bulgaricus and $S$. thermophilus after the addition of $L$. case $i$ to yogurt.

Effects of probiotics on yogurt properties:

The behaviour of probiotic organisms can be explained based on theireffects on yogurt properties. The production of lactic acid in yogurt increased when probiotic bacteria were used; B. bifidum increased lactic acid from 0.76 to $0.89 \%$ when it was used with $S$. thermophilus, and from 0.43 to $0.88 \%$ when it was used with $L$. delbrueckii subsp. bulgaricus. Acid production by yogurt bacteria is affected by the species; for example, $S$. thermophilus produced greater acidity with B. adolescentis (Khedkar, Dave, \& Sannabhadti, 1994). The best incorporation was seen using B. adolescentis with $S$. thermophilus. The behaviour of yogurt cultures was improved after addition of L. acidophilus and B. bifidum together compared to either L. acidophilus or B. bifidum alone (Srinivas, Prabha, \& Shankar, 1997). Yamamah et al. (2005) found an improvement in acidity after the addition of $5 \%$ B. bifidum in yogurt cultures (0.80-0.86\% lactic acid); nevertheless, addition of $2 \%$ L. acidophilus formed low acid $(0.75 \%$ lactic acid). The inclusion of probiotic cultures such as L. acidophilus La5, L. acidophilus 1748, Lactobacillus rhamnosus GG, L. reuterii SD 2112 and B. animalis BB12 increased lactic acid production in ultra-high temperature milk after $48 \mathrm{~h}$ of fermentation at $37^{\circ} \mathrm{C}(\varnothing$ stlie, Helland, \& Narvhus, 2003). (Hadadji \& Bensoltane, 2006) showed an increase in acidification by $B$. longum and L. acidophilus during mixed culturing at $45^{\circ} \mathrm{C}$; however L. plantarum and Lactobacillus paracasei subsp. Tolerans produced minimal acid in yogurt but did not show any inhibitory action towards or from yogurt cultures (Maragkoudakis, et al., 2006).

Growth of $S$. thermophilus produced more lactic acid in yogurt than $L$. delbrueckii subsp. bulgaricus during storage; L. acidophilus and B. bifidum also produced an increased lactic content. Addition of $P$. freudenreichii subsp. shermanii or $B$. bifidumto yogurt starters also increased the content of lactic acid (Bizzozero \& Sprocati, 2001). In contrast with previous results mentioned that the addition of probiotic decreased acid development in yogurt during storage (Kailasapathy, 2006). Probiotic bacteria such as $L$. acidophilus and B. bifidum produced yogurt with good flavour after $5 \mathrm{~h}$ incubation at $40^{\circ} \mathrm{C}$. Volatile acidity and diacetyl production in yogurt were improved when Leuconostoc cremoris or B. bifidum and P. freudenreichiisubsp. shermanii were added (Sarkar \& Misra, 2001). Addition of $B$. bifidum and P. freudenreichii subsp. shermanii enhanced volatile acidity and the combined diacetyl and acetoin content of yogurt. The addition of Bifidobacterium spp. to yogurt produced acetic and propionic acids (Adhikari, Grun, Mustapha, \& Fernando, 2002). The acetaldehyde content of yogurt increased with the addition of B. bifidum; nevertheless, more addition of $L$. acidophilus produced less acetaldehyde content (Yamamah et al. 2005). Enrichment of milk with amino acid (threonine) improves acetaldehyde amount in yogurt has Bifidobacterium spp. and/or L. acidophilus (Baranowska, 2006). Yogurt inoculated with L. acidophilus MJLA1 could not be distinguished from the control sample in its flavours during storage (Heenan, Adams, Hosken, \& Fleet, 2004). Probiotic yogurts showed high contents of organic acids and aroma compounds (Cruz, et al., 2012).

The addition of L. acidophilus and B. bifidum to yogurt resulted in the exhibition of higher proteolytic activity compared to either L. acidophilus or B. bifidumalone (Srinivas, et al., 1997). A greater quantity of soluble peptides is manifest in probiotic yogurt produced using yogurt culture, bifidobacteria and L. Acidophilus, also probiotic yogurts showed high proteolytic activity (Al-Sheraji, Ismail, Manap, Mustafa, \& Yusof, 2012a Cruz, et al., 2012).

Addition of Propionibacterium jensenii and B. animalis caused an increase in the folic acid content of yogurt (Crittenden, Martinez, \& Playne, 2003). L. acidophilus La 1 enhanced blood contains of vitamin $\mathrm{B}_{12}$ and folate; bio-yogurt has L. acidophilus La 1 and was thereby confirmed to be better than normal yogurt (Mohammad, Molloy, Scott, \& Hussein, 2006).

$\beta$-galactosidase is an enzyme that hydrolyses the $\beta$ glycosidicbond formed between a galactose and a glucose molecule in lactose. Probiotic yogurt has higher levels of $\beta$-galactosidase activity than plain yogurt. Incorporation of $B$. bifidum and $P$. freudenreichii subsp. shermanii during yogurt making processes increased $\beta$-galactosidase activity through 7 days of storage at $8 \pm 1^{\circ} \mathrm{C}$ (Sarkar \& Misra, 2001). Consumption of yogurt has B. animalis by lactose-intolerant subjects produced an important raise in the bifidobacterium numbers and decreased lactose-intolerance (Zhong, Huang, He, \& Harmsen, 2006).

\section{Health benefits of probiotics:}

Several potential health benefits are in support of products including probiotic bacteria, such as antimicrobial action, improved lactose metabolism (Ankolekar, et al., 2011 Shah, 2000b), anti-mutagenic properties, prevention of cancer (Ankolekar, et al., 2011 Shah, 2007), lowering of serum cholesterol, anti-diarrhoeal properties (Shah, 2004), immune system stimulation, anti-hyperglycemia and hypertension properties (Apostolidis, Kwon, Ghaedian, \& Shetty, 2007), improved mineral absorption(Ankolekar, et al., 2011 Gilman \& Cashman, 2006 Mutus,, et al., 2006), reduction in inflammatory gut infection and inhibition of Helicobacter pylori (Apostolidis, et al., 2011 Kurmann \& Robinson, 1991 Shah, 2000a, 2004). Some of these health benefits are well recognized, while others have not been demonstrated in animal studies. Nevertheless, further human trails are necessary to validate these hypotheses. 


\section{The Influence Of Specialized Physical Education Program For Students With Health \\ Issues

Probiotic bacteria promote the health benefits depend on the kind of strain. It is significant to mention that no single species gives all the health benefits, not even types of the same species, and not all strains of the same species will be valuable against diverse health situations. The strains L. rhamnosus GG, S. cerevisiae Boulardii, L. casei Shirota, and $B$. animalis $\mathrm{Bb}-12$ have the significant demonstrated human health benefits regarding to lactose malabsorption, rotaviral diarrhoea, antibiotic-associated diarrhoea, and Clostridium difficile diarrhoea (Playne, Bennett, \& Smithers, 2003 ). There is sufficient confirmation to prove the report that oral ingestion of Lactobacillus and Bifidobacterium is able to sustain an ideal balance of microbial counts in the gut.

Effects of probiotics on cholesterol levels and cardiovascular risk factors:

The level danger cause for cardiovascular disease and important markers of blood cholesterol is mainly LDLcholesterol which has been associated with a raised risk. Serum cholesterol level is affected by dietary saturated fat, cholesterol ingestion. Ingestion of fermented dairy containing probiotic bacteria $\left(10^{9} \mathrm{CFU} / \mathrm{g}\right)$ by hypercholesterolemic human subjects reduced cholesterol from 3.0 to $1.5 \mathrm{~g} / \mathrm{L}$ Liong \& Shah (2006) M.T. Liong and N.P. Shah, Effects of Lactobacillus casei synbiotic on serum lipoprotein, intestinal microflora, and organic acids in rats, Journal of Dairy Science 89 (2006), pp. 1390-1399. View Record in Scopus Cited By in Scopus ( (Shah, 2007). Probiotic bacteria are known to deconjugate bile salts: absorption of lipid by deconjugated bile acid is not as easy as its conjugated type, leading to a lowering in cholesterol level. $L$. acidophilus is also known to assimilate cholesterol throughout survive, making it inaccessible for absorption into the bloodstream (Klaver \& Van der Meer, 1993). The effects of probiotics on serum cholesterol are summarised in Table 2 .

Plasma lipoprotein synthesis and metabolism:

Liver and gut consider the major organs in the body responsible for synthesis and transport of lipoproteins. The cystic duct passes bile from the gallbladder to the intestine. The liver forms the bile, but it is shifted to the gallbladder and stays there until use. When a fatty food reaches in the small intestine, bile salts are marshalled to assist with emulsification of the fats. This lets fat digestion and absorption in the intestine easy. In the epithelial cells of the intestine fatty acids, triglycerides, and cholesterol are combined and covered with a layer of protein to result chylomicrons. The body's cholesterol produces from fresh biosynthesis is less than $50 \%$, in the liver is nearly $10 \%$, and in the intestine is $15 \%$ (Kaplan \& Pesce, 2009). "Cholesterol synthesis happens in the microsomes and cytoplasm from the two-carbon acetate group of acetyl-CoA (Dessi \& Batetta, 2003) The biosynthesis of cholesterol follows these steps:

(1)Conversion of Acetyl-CoA to 3-hydroxy-3methylglutaryl-CoA (HMG-CoA), (2)Conversion of HMG-CoA to mevalonate,

(3)Mevalonate is converted to isopentenyl pyrophosphate,

(4)Isopentenyl pyrophosphate is converted to squalene,
(5)Conversion of squalene to cholesterol (Dessi \& Batetta, 2003)."

In normal adults, about $1 \mathrm{~g}$ of cholesterol is created and $0.3 \mathrm{~g}$ is ingested from food per day. The body keeps a moderately stable quantity of cholesterol $(150-200 \mathrm{mg} / \mathrm{dL})$. This is made mostly during controlling the level of de novo synthesis. Nutritional ingestion of cholesterol moderately controls the level of cholesterol synthesis. These cholesterols after that are utilized for the synthesis of cell membranes and in the formation of steroid hormones and bile acids (Croft, et al., 1988). "Three separate mechanisms regulate the body's constant supply of cholesterol from cells (Kaplan \& Pesce, 2009).

In normal adults, about $1 \mathrm{~g}$ of cholesterol is created and $0.3 \mathrm{~g}$ is ingested from food per day. The body keeps a moderately stable quantity of cholesterol (150-200 mg/dL). This is made mostly during controlling the level of de novo synthesis. Nutritional ingestion of cholesterol moderately controls the level of cholesterol synthesis. These cholesterols after that are utilized for the synthesis of cell membranes and in the formation of steroid hormones and bile acids (Croft, et al., 1988). "Three separate mechanisms regulate the body's constant supply of cholesterol from cells (Kaplan \& Pesce, 2009).

(1)Regulation of HMG-CoA reductase,

(2)Regulation of extra intracellular free cholesterol via Acyl-CoA,

(3)Lecithin-cholesterol acyltransferase (LCAT)"

Atherosclerotic plaque happens in the arteries by low density lipoprotein cholesterol (LDL-C) which can be oxidized by very reactive, oxidative compounds in the body that called free radicals. Atherosclerotic plaque in the body can reduce by antioxidants compounds (Jialal, 1998), such as vitamins A, C, and E, and other nutrients. Antioxidants can inhibit the formation and oxidation of free radicals. Also vitamins, A, E, and C, assist to reduce LDL-C oxidation.

High Density Lipoprotein (HDL-C) which forms also in the liver and considers different kind of lipoprotein from LDL-C and VLDL-C. It contains fewer amounts of triglyceride and cholesterol, but contains a particular protein coating. HDL-C gathers the extra cholesterol that cholesterolmetabolizing cells do not use. Unutilized cholesterols from arteries, liver, and other tissues are moved back to HDL-C by Lecithin-cholesterol acyl transferaseis (LCAT) and absorbed by HDL-C. LCAT and HDL-C can remove some oxidized LDL-C as well (Höckerstedt, Jauhiainen, \& Tikkanen, 2004). The major apolipoprotein in HDL-C is Apo-A-1 which presents a main role: it gathers extra cholesterol from all cells in the body and transports it to the liver (Nissen, et al., 2003). Cardiovascular disease risk can increase if the ratio between Apo B/Apo A-1 is high due to possibility of cholesterol places in the walls of the arteries but if the ratio between Apo B/Apo A-1 is low that mean cardiovascular disease risk is low (Walldius \& Jungner, 2004).

Probiotics' mechanism of action on lipids:

Probiotics bacteria ferment indigestible carbohydrates in the intestine to produce short chain fatty acids (SCFAs). However SCFAs are produced from peptides, polysaccharides, proteins, and oligosaccharides by probiotic bacteria 
Table 2. Effectsof probiotics on serum cholesterol

\begin{tabular}{|c|c|c|}
\hline Probiotic & Probiotic function & Reference \\
\hline L. acidophilus & Lowered serum total cholesterol (TC) levels. & $\begin{array}{l}\text { (Ouwehand, Salminen, \& } \\
\text { Isolauri, 2002) }\end{array}$ \\
\hline $\begin{array}{l}\text { L. acidophilus; L. casei ASCC 1520, ASCC } \\
\text { 1521, ASCC 292, ATCC 15820, and L. } \\
\text { acidophilus ATCC } 4962\end{array}$ & Assimilated more than $25 \mu \mathrm{g} \mathrm{mL}-1 \mathrm{TC}$ & (Liong \& Shah, 2005) \\
\hline Human strain of Enterococcus faecium & $\begin{array}{l}\text { Resulting the lowering of plasma TC by } 0.37-0.41 \\
\text { mmol/L after } 6 \text { wk. } \\
\text { Significantly larger decrease in serum low density } \\
\text { lipoprotein cholesterol (LDL-C); concentrations } \\
\text { decreased throughout the study. }\end{array}$ & $\begin{array}{l}\text { (Agerbaek, Gerdes, \& } \\
\text { Richelsen, 1995) } \\
\text { (Richelsen, Kristensen, } \\
\text { \& Pedersen, 1996) }\end{array}$ \\
\hline Ent. faecium (Gaio) & $\begin{array}{l}\text { Reduced both TC and LDL-C by } 4 \% \text { and } 5 \% \text {, } \\
\text { respectively }\end{array}$ & $\begin{array}{l}\text { (Agerholm-Larsen, Bell, } \\
\text { Grunwald, \& Astrup, } \\
2000)\end{array}$ \\
\hline L. casei TMC 0409 & $\begin{array}{l}\text { Increased high density lipoprotein cholesterol } \\
\text { (HDL-C); also reduced the levels of triglycerides (TG) } \\
\text { significantly. }\end{array}$ & $\begin{array}{l}\text { Kawase, Hashimoto, } \\
\text { Hosoda, Morita, \& } \\
\text { Hosono, 2000) }\end{array}$ \\
\hline S. thermophilus TMC 1543 & Increased HDL-C. Levels of TG were also reduced & (Kawase et al. 1999) \\
\hline B. longum 913; L. acidophilus 145 & $\begin{array}{l}\text { Increased HDL-C content by } 0.3 \mathrm{mmol} \mathrm{L}-1 \text { and } \\
\text { decreased ratio of LDL-C to HDL-C from } 3.24 \text { to } 2.48 \\
(\mathrm{p}=0.001) .\end{array}$ & $\begin{array}{l}\text { (Kiessling, Schneider, \& } \\
\text { Jahreisl, 2002) }\end{array}$ \\
\hline L. gasseri SBT0270, SBT0274 & Exerted hypocholesterolaemic effect & (Hosono, 2000) \\
\hline L. reuteri CRL 1098 (104 cells d-1) & $\begin{array}{l}\text { Resulting a } 40 \% \text { lowering in } \mathrm{TG} \text { and a } 20 \% \text { raise in the } \\
\text { ratio of HDL-C to LDL-C. }\end{array}$ & $\begin{array}{l}\text { (Taranto, Medici, } \\
\text { Perdigon, Ruiz Holgado, } \\
\text { \& Valdez, 1998) }\end{array}$ \\
\hline B. longum BL1 & $\begin{array}{l}\text { Result to a significant reduction of plasma contents of } \\
\text { TC, LDL-C, and TG. }\end{array}$ & (Xiao, et al., 2003) \\
\hline L. brevis NR1C1684; Ent. faecalis & Assimilated more cholesterol & $\begin{array}{l}\text { (Pereira \& Gibson, } \\
2002 b)\end{array}$ \\
\hline B. lactis $\mathrm{Bb}-12$ or $\mathrm{B}$. longum $\mathrm{Bb}-46$ & $\begin{array}{l}\text { Significantly lowered levels of plasma TC and VLDL-C } \\
+ \text { LDL-C and promoted faecal excretion of bile acids }\end{array}$ & (El-Gawad, et al., 2005) \\
\hline $\begin{array}{l}\text { Lactobacillus strains } \\
\text { (NTU } 101 \text { and 102) }\end{array}$ & Lowered TC levels in serum and liver. & $\begin{array}{l}\text { (Chiu, Lu, Tseng, \& } \\
\text { Pan, 2006)\{Chiu, } 2006 \\
\# 144\}\end{array}$ \\
\hline B. animalis spp. lactis (Bb12) & $\begin{array}{l}\text { Cholesterol levels were lowered by up to } 48 \% \text { after } \\
\text { incubation with Bb12 }\end{array}$ & (Alhaj, et al., 2010) \\
\hline B. longum SPM1207 & $\begin{array}{l}\text { Has higher possible to be utilized as a } \\
\text { cholesterol-reduction mean }\end{array}$ & (Shin, et al., 2010) \\
\hline B. longum BB536 & $\begin{array}{l}\text { Reduced TC, LDL-C and VLDL in plasma of } \\
\text { hypercholesterolaemic rats }\end{array}$ & $\begin{array}{l}\text { (Al-Sheraji, et al., } \\
2012 \text { b) }\end{array}$ \\
\hline B. pseudocatenulatum G4 & $\begin{array}{l}\text { Decrease cholesterol levels in plasma of } \\
\text { hypercholesterolaemic rats }\end{array}$ & $\begin{array}{l}\text { (Al-Sheraji, et al., } \\
2012 \mathrm{~b})\end{array}$ \\
\hline
\end{tabular}

but in carbohydrates consider the main source of SCFAs (St-Onge, Farnworth, \& Jones, 2000). Indigestible carbohydrates are hydrolyzed by a diversity of hydrolytic enzymes which are produced by probiotics and let the probiotics to ferment their sugar content. SCFAs such as propionate can reduce the levels of cholesterol in blood by inhibition the forming of hepatic cholesterol. Propionate reaches the liver by the portal vein and inhibits the cholesterol synthesis pathway by inhibiting HMG-CoA reductase (Levrat, et al., 1994), just as the statins presented inFigure 1 . It also acts to redirect plasma cholesterol towards the liver (De Preter, Coopmans, Rutgeerts, \& Verbeke, 2006).

Source: (Kirk, 1999).

Combination of bile salts, cholesterol, and phospholipids produces micelles which play a important function in the absorption of cholesterol in the gut. Bile acids are produced during deconjugation of bile salts in the small intestine. Micelle production can be inhibited by bile acid hydrolase (BSH) which produces from probiotics. BSH converts conjugated bile acids to unconjugated bile salt in the enterohep- atic circulation. It cleaves the peptide linkages in bile acids that link amino groups in amino acid to carboxyl groups in the bile acids during the bile acids formation from cholesterol and either glycine or taurine in the liver. The resulting unconjugated bile acids precipitate as shown inFigure 2 ; thus new bile acids is needed to produce micelles so more cholesterol is converted to bile salts in a homeostatic response, consequential the cholesterol level will decrease in blood Figure 3 (Begley, et al., 2006).

Source: (Begley, et al., 2006).

Source:(Ooi \& Liong, 2010).

Probiotics deconjugate bile acids and hydrolyze bile salts by hydroxy steroid dehydrogenase, and bile acid hydrolase, thus, the bile acids' enterohepatic circulation is stopped (Ahn, Kim, Lim, Baek, \& Kim, 2003 De Boever \& Verstraete, 2001). Probiotic bacteria can bind cholesterol up in the small intestines, thus the absorption of cholesterol from the gut is decreased Figure 4 (Hosono, 1999)and incorporating it into their cellular membranes (Kimoto, Ohmomo, \& Okamoto, 2002). Cholesterol can be taken in during growth 


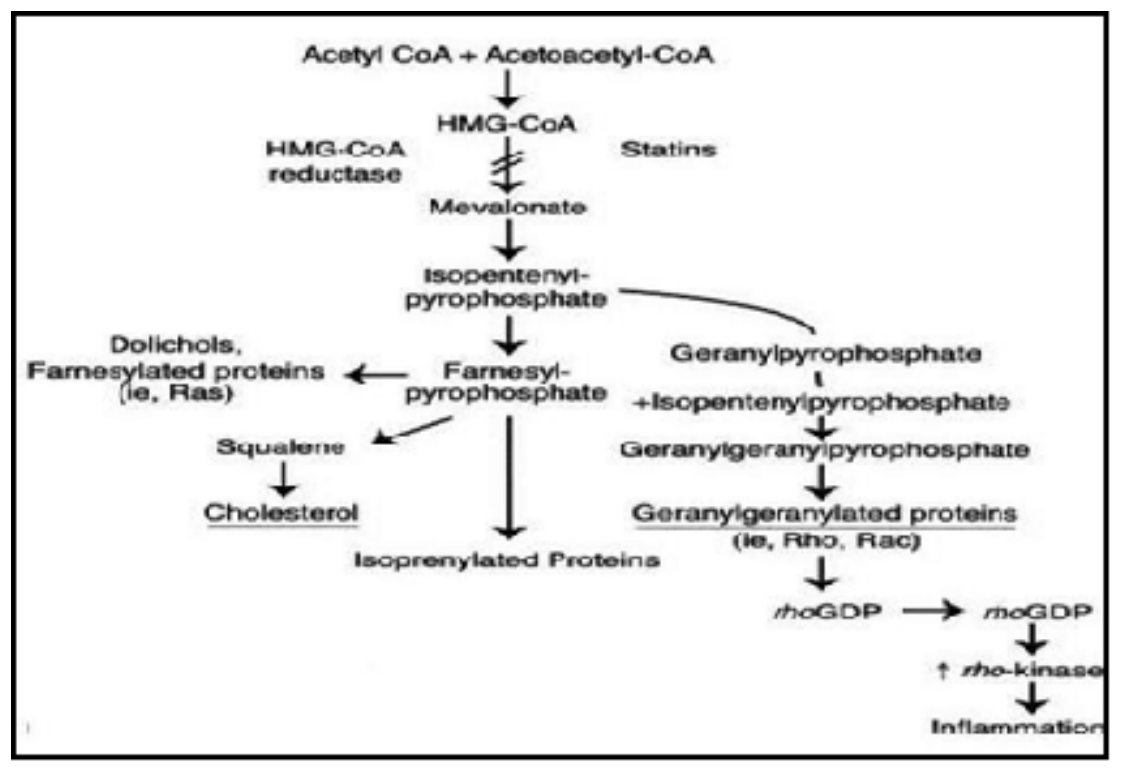

Figure 1. Inhibition of HMG-CoA reductase pathway

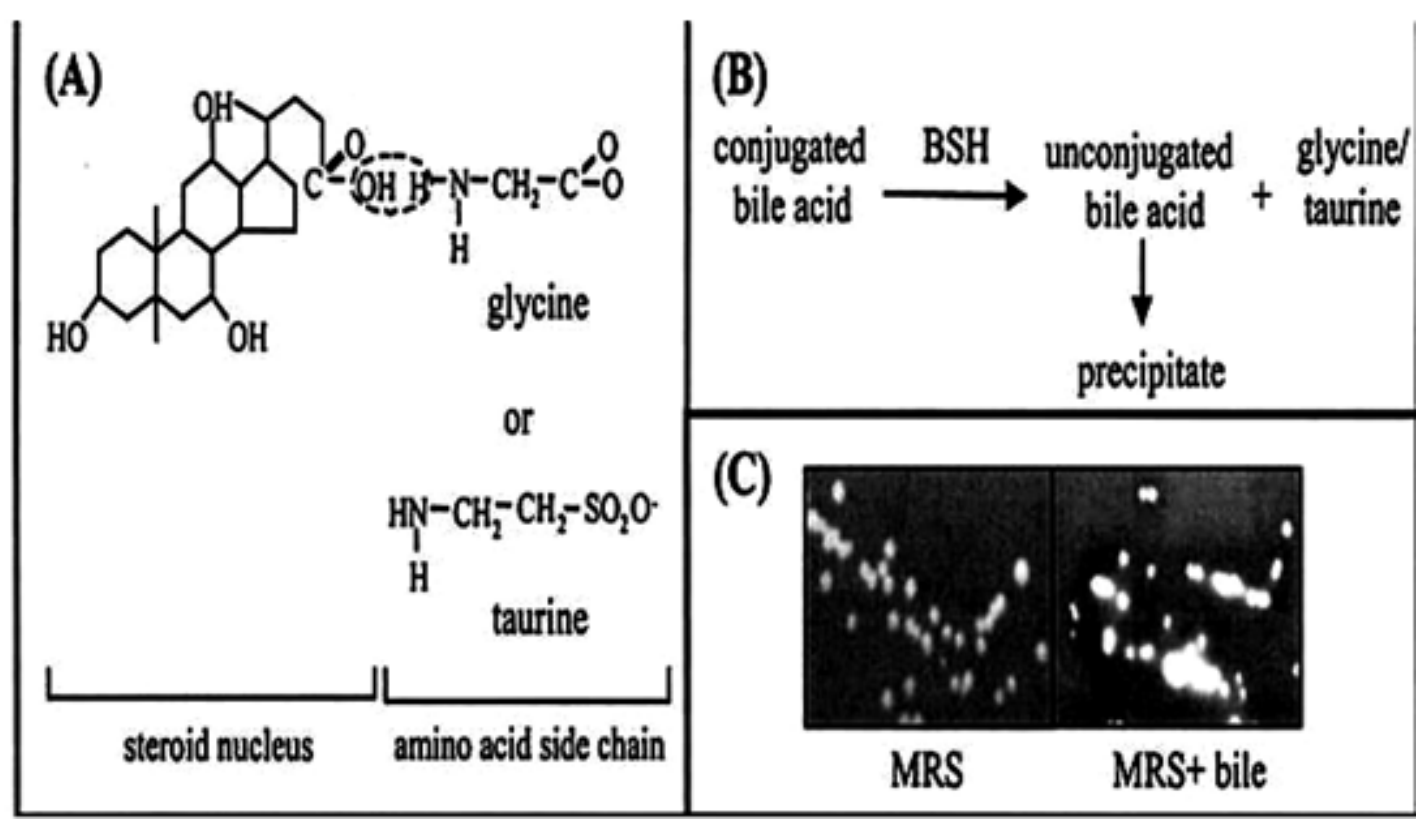

Figure 2. Bile acids precipitated byBSH pathway. BSH: bile acids hydrolase

of probiotics (Noh, Kim, \& Gilliland, 1997). The previous activities of probiotics contribute to the cholesterol reducing performances.

Source:(Ooi \& Liong, 2010)

\section{CONCLUSIONS:}

Probiotic bacteria are live microorganisms which when ingested in sufficient numbers exert health benefits such as reduction of hypercholesterol, lowering of intestine $\mathrm{pH}$, formation of several digestive enzymes and vitamins, formation of antibacterial compounds, e.g., organic acids, bacteriocins, hydrogen peroxide, diacetyl, acetaldehyde, lactoperoxidase, lactones and other unidentified substances. Other benefits include contributions to reconstruction of regular intestinal bacteria after disorders resulted by diarrhoeas, antibiotic treatment and radiotherapy, lowering of cholesterol content in the serum, motivation of immune roles, inhibition of bacterial diseases, elimination of carcinogens and enhancement of calcium absorption and the decrease of faecal enzyme action. 


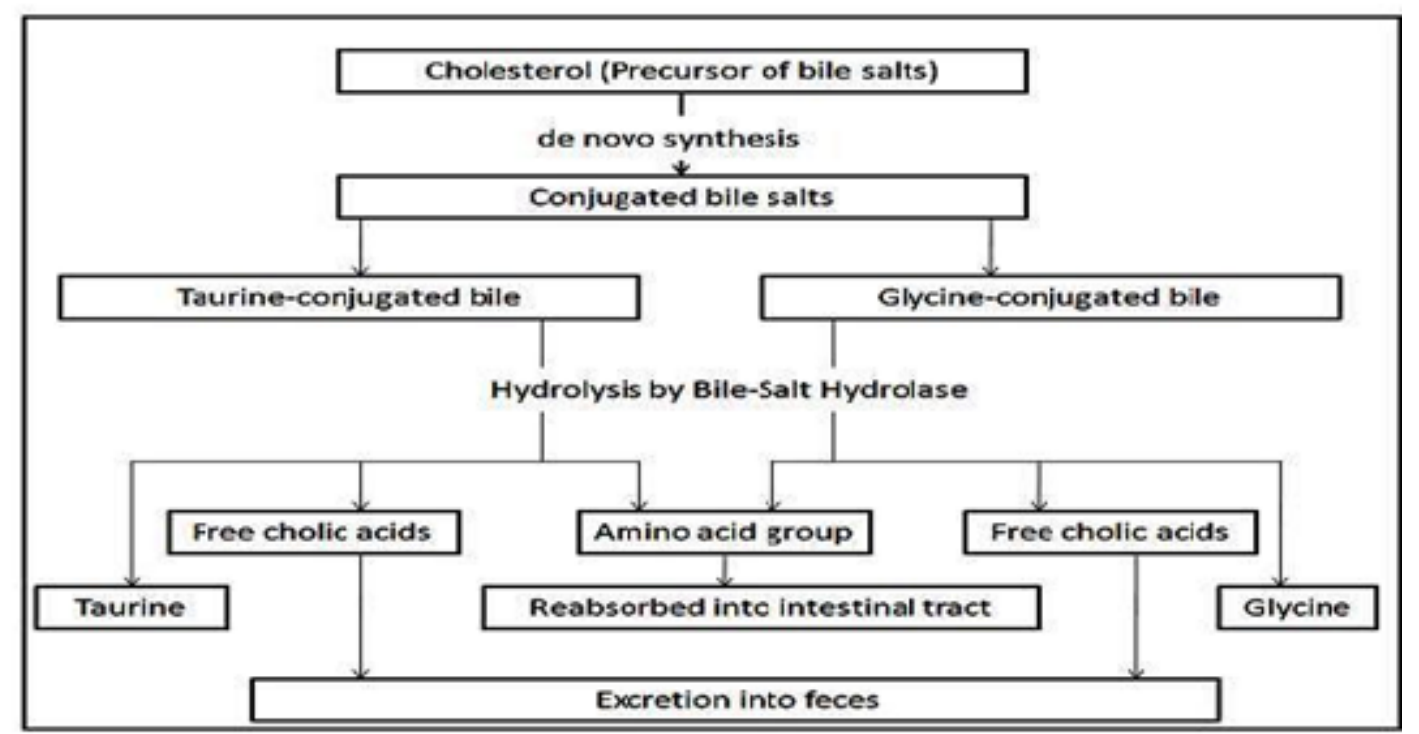

Figure 3. Cholesterol as the precursor for the synthesisof new bile acids and thehypocholesterolemic role of bile salt hydrolase

$(\Delta)$

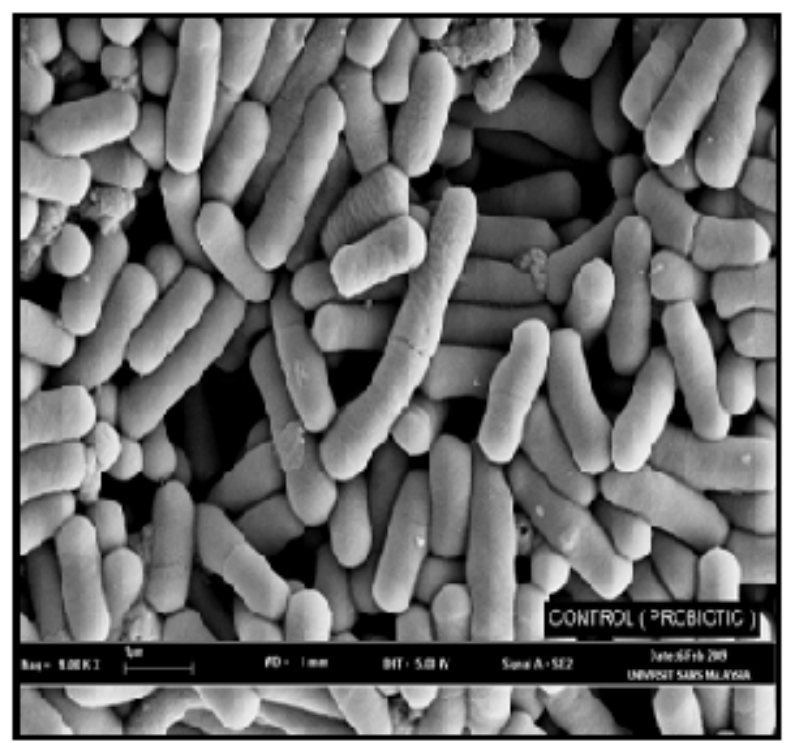

(B)

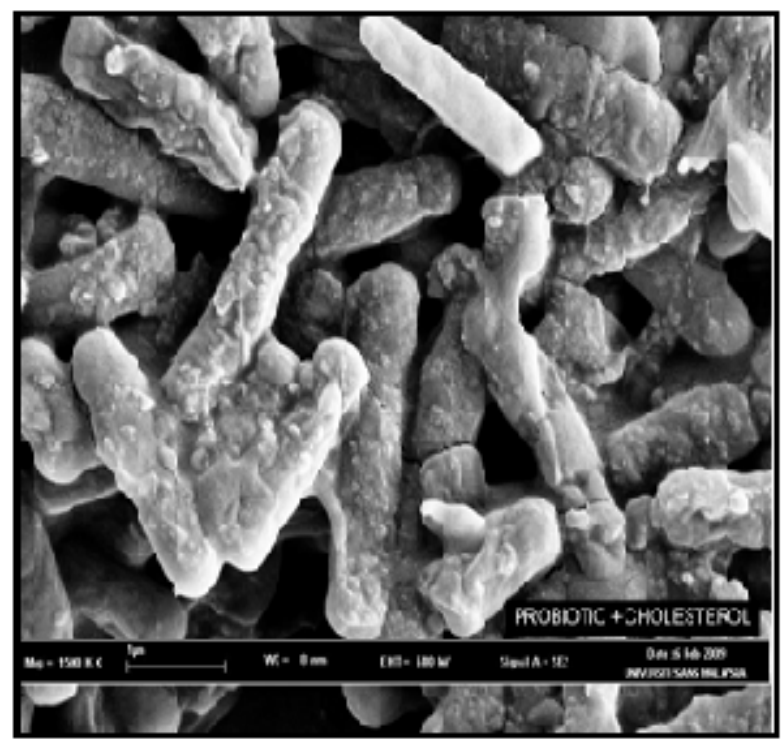

Figure 4. Scanning electron micrograph of Lactobacillus bulgaricus cultivatedin(A) media without cholesterol and (B) broth supplemented with cholesterol(100 $\mathrm{mM})$ 


\section{The Influence Of Specialized Physical Education Program For Students With Health \\ Issues

\section{ACKNOWLEDGEMENT:}

The authors would like to thank the Department of Nutrition and Dietetics, Faculty of Medicine and Health Sciences, Universiti Putra Malaysia, Malaysia. We also would like to acknowledge Research University Grant Scheme (RUGS) (Project No: 02-01-09-0703RU) from the Universiti Putra Malaysia, Malaysia.

\section{REFERENCES}

[1] Adhikari K, Grun IU, Mustapha A, Fernando LN. Changes in the profile of organic acids in plain set and stirred yogurts during manufacture and refrigerated storage. Journal of Food Quality. 2002;25:435-451.

[2] Hypocholesterolaemic effect of a new fermented milk product in healthy middle-aged men. European journal of clinical nutrition. 1995;49:346.

[3] The effect of a probiotic milk product on plasma cholesterol: a meta-analysis of short-term intervention studies. European journal of clinical nutrition. 2000;54:856.

[4] Deconjugation of bile salts by Lactobacillus acidophilus isolates. International Dairy Journal. 2003;13:303-311.

[5] Viability and Activity of Bifidobacteria During Refrigerated Storage of Yoghurt Containing Mangifera pajang Fibrous Polysaccharides. Journal of Food Science. 2012;77:624-630.

[6] Al-Sheraji SH, Ismail A, Manap MY, Mustafa S, Yusof RM, Hassan FA. Hypocholesterolaemic effect of yoghurt containing Bifidobacterium pseudocatenulatum G4 or Bifidobacterium longum BB536. Food Chemistry. 2012;135:356-361.

[7] Hypocholesterolaemic effect of Bifidobacterium animalis subsp. lactis (Bb12) and trypsin casein hydrolysate. Food Chemistry. 2010;123:430-435.

[8] Inhibitory potential of tea polyphenolics and influence of extraction time against helicobacter pylori and lack of inhibition of beneficial lactic acid bacteria. Journal of Medicinal Food. 2011;14:1321-1329.

[9] Anukam K, Osazuwa E, Ahonkhai I, Ngwu M, Osemene G, Bruce AW, et al. Augmentation of antimicrobial metronidazole therapy of bacterial vaginosis with oral probiotic Lactobacillus rhamnosus GR-1 and Lactobacillus reuteri RC14: randomized, double-blind, placebo controlled trial. Microbes and Infection. 2006;8:1450-1454.

[10] Fermentation of milk and soymilk by Lactobacillus bulgaricus and Lactobacillus acidophilus enhances functionality for potential dietary management of hyperglycemia and hypertension. Food Biotechnology. 2007;21:217-236.

[11] Inhibition of Helicobacter pylori by Fermented Milk and Soymilk Using Select Lactic Acid Bacteria and Link to. vol. 25. Taylor \& Francis; 2011.

[12] Incorporation of selected nutraceuticals and probiotic bacteria into a fermented milk. International Dairy Journal. 2005; $15: 1184-1190$

[13] Baranowska M. Intensification of the synthesis of flavour compounds in yogurt by milk enrichment with their precursors. Polish Journal of Food and Nutrition Sciences. 2006;15:5-11.

[14] Bile Salt Hydrolase Activity in Probiotics. Applied and Environmental Microbiology. 2006;72(1729):1738.

[15] Chemical characteristics of yoghurt samples from the market. Industrie Alimentari. 2001;40:7-10.

[16] The determination of viable counts in probiotic cultures microencapsulated by spray-coating. Food Microbiology. 2010;27:1104-1111.
[17] The effects of Lactobacillus-fermented milk on lipid metabolism in hamsters fed on high-cholesterol diet. Applied microbiology and biotechnology. 2006;71:238-245.

[18] Effect of whey protein concentrate supplementation on the viability of Bifidobacterium bifidum in probiotic yoghurt. Journal of Food Science \& Technology. 2006;43:552-554.

[19] Crittenden RG, Martinez NR, Playne MJ. Synthesis and utilisation of folate by yoghurt starter cultures and probiotic bacteria. International Journal of Food Microbiology. 2003;80:217-222.

[20] Cardiovascular risk in parents of children with extreme lipoprotein cholesterol levels. Southern Medical Journal. 1988;81:341-353.

[21] Glucose oxidase: A potential option to decrease the oxidative stress in stirred probiotic yogurt. LWT - Food. Science and Technology. 2012;47:512-515.

[22] Viability of yoghurt and probiotic bacteria in yoghurts made from commercial starter cultures. International Dairy Journal. 1997;7:31-41.

[23] Bile salt deconjugation by Lactobacillus plantarum 80 and its implication for bacterial toxicity. Journal of applied microbiology. 2001;87:345-352.

[24] Influence of long-term administration of lactulose and Saccharomyces boulardii on the colonic generation of phenolic compounds in healthy human subjects. Journal of the American College of Nutrition. 2006;25:541-549.

[25] Overview - Intracellular cholesterol homeostasis. Springer; 2003.

[26] Santo AP, Perego P, Converti A, Oliveira MN. [26] do Espírito. vol. 22; 2011.

[27] The hypocholesterolemic effect of milk yoghurt and soy-yoghurt containing bifidobacteria in rats fed on a cholesterol-enriched diet. International Dairy Journal. 2005; $15: 37-44$.

[28] The effect of daily consumption of probiotic and conventional yoghurt on oxidant and anti-oxidant parameters in plasma of young healthy women. International journal for vitamin and nutrition research. Internationale Zeitschrift fur Vitamin- und Ernahrungsforschung. Journal international de vitaminologie et de. 2007;77:79-88.

[29] Growth of probiotic bacteria and bifidobacteria in a soy yogurt formulation. International Journal of Food Microbiology. $2007 ; 116: 174-181$

[30] The role of protective and probiotic cultures in food and feed and their impact in food safety. vol. 22; 2011.

[31] Viability during storage of selected probiotic lactobacilli and bifidobacteria in a yoghurt-like product. Journal of Food Science. 2002;67:3091-3095.

[32] The effect of probiotic bacteria on transepithelial calcium transport and calcium uptake in human intestinal-like Caco2 cells. vol. 7; 2006.

[33] Cruz A, Buriti FCA, Souza CH, Faria JAF, Saad SMI. Probiotic cheese: health benefits, technological and stability aspects. Trends in Food Science \& Technology. 2009;20:344354.

[34] Growth and lactic acid production by Bifidobacterium longum and Lactobacillus acidophilus in goat's milk. African Journal of Biotechnology. 2006;5:505-509.

[35] The Production of Yoghurt with Probiotic Bacteria Isolated from Infants in Jordan. Pakistan Journal of Nutrition. 2004;3:290-293.

[36] Survival and sensory acceptability of probiotic microorganisms in a nonfermented frozen vegetarian dessert. LWT Food Science and. Technology. 2004;37:461-466.

[37] Heller KJ. Probiotic bacteria in fermented foods: product characteristics and starter organisms. The American Jour- 
nal of Clinical Nutrition. 2001;73:374-379.

[38] Lecithin/cholesterol acyltransferase inducessstradiol esterification in High-Density Lipoprotein, increasing its antioxidant potential. The Journal of Clinical of Endocrinology and Metabolism. 2004;89:5088-105093.

[39] Hosono A. Bile Tolerance, Taurocholate Deconjugation, and Binding of Cholesterol by Lactobacillus gasseri Strains. Journal of dairy science. 1999;82:243-248.

[40] Hosono A. Effect of Administration of Lactobacillus gasseri on Serum Lipids and Fecal Steroids in Hypercholesterolemic Rats. Journal of dairy science. 2000;83:1705-1711.

[41] Viability of bifidobacteria in commercial yogurt products in North Carolina during refrigerated storage. International Journal of Dairy Technology. 2006;59:272-277.

[42] Probiotics: Use in Allergic Disorders: A Nutrition, Allergy, Mucosal Immunology, and Intestinal Microbiota (NAMI). Research Group Report Journal of Clinical Gastroenterology. 2008;42:91-96.

[43] Jialal I. Evolving lipoprotein risk factors: lipoprotein (a) and oxidized low-density lipoprotein. Clinical chemistry. 1998;44:1827-1832.

[44] Probiotics for the prevention of pediatric antibioticassociated diarrhea. Cochrane Database of Systematic Reviews. 2007;18:004827.

[45] Kailasapathy K. Survival of free and encapsulated probiotic bacteria and their effect on the sensory properties of yoghurt. LWT - Food. Science and Technology. 2006;39:12211227.

[46] Clinical chemistry: theory, analysis, and correlation. Mosby; 2009.

[47] Effect of administration of fermented milk containing whey protein concentrate to rats and healthy men on serum lipids and blood pressure. Journal of dairy science. 2000;83:255263.

[48] Associative relation of bifidobacteria with lactic cultures. Indian Journal of Dairy Science. 1994;47:692-694.

[49] ORIGINAL COMMUNICATION Long-term consumption of fermented dairy products over 6 months increases HDL cholesterol. European journal of clinical nutrition. 2002;56:843-849.

[50] Cholesterol removal from media by lactococci. Journal of dairy science. 2002;85:3182-3188.

[51] Kirk, A. M. (1999). Genes That Overcome Drug-Induced Cholesterol Auxotropy. University of Utah olesterol removal from media by lactococci. Journal of

[52] Klaver, F., \& Van der Meer, R. (1993). The assumed assimilation of cholesterol by Lactobacilli and Bifidobacterium bifidum is due to their bile salt-deconjugating activity. Applied and Environmental Microbiology, 59, 1120-1124.

[53] Krasaekoopt, W., Bhandari, B., \& Deeth, H. C. (2006). Survival of probiotics encapsulated in chitosan-coated alginate beads in yoghurt from UHT- and conventionally treated milk during storage. LWT Food Science and Technology, 39, 177-183.

[54] Kurmann, J., \& Robinson, R. (1991). The health potential of products containing bifidobacteria.

[55] Kurugöl, Z., \& Koturoğlu, G. (2005). Effects of Saccharomyces boulardii in children with acute diarrhoea. Acta Paediatrica, 94, 44-47.

[56] Lamoureux, L., Roy, D., \& Gauthier, S. F. (2002). Production of Oligosaccharides in Yogurt Containing Bifidobacteria and Yogurt Cultures. Journal of dairy science, 85, 1058-1069.

[57] Levrat, M. A., Favier, M. L., Moundras, C., Rémésy, C., Demigné, C., \& Morand, C. (1994). Role of dietary propionic acid and bile acid excretion in the hypocholesterolemic effects of oligosaccharides in rats. The Journal of nutrition, 124, 531 .
[58] Liong, M. T., \& Shah, N. P. (2005). Acid and bile tolerance and cholesterol removal ability of lactobacilli strains. Journal of dairy science, $88,55-66$.

[59] Lora, K. R., Morse, K. L., Gonzalez-Kruger, G. E., \& Driskell, J. A. (2007). High saturated fat and cholesterol intakes and abnormal plasma lipid concentrations observed in a group of 4- to 8-year-old children of Latino immigrants in rural Nebraska. Nutrition Research, 27, 483-491.

[60] Manson, J. E., Tosteson, H., Ridker, P. M., Satterfield, S., Hebert, P., O'Connor, G. T., Buring, J. E., \& Hennekens, C. H. (1992). The Primary Prevention of Myocardial Infarction. New England Journal of Medicine, 326, 1406-1416.

[61] Maragkoudakis, P. A., Miaris, C., Rojez, P., Manalis, N., Magkanari, F., Kalantzopoulos, G., \& Tsakalidou, E. (2006). Production of traditional Greek yoghurt using Lactobacillus strains with probiotic potential as starter adjuncts. International Dairy Journal, 16, 52-60.

[62] Mattila-Sandholm, T., \& Salminen, S. (1998). Up-to-date on probiotic in Europe. Gastroenterology International, 11, 8-16.

[63] McComas, K. A., \& Gilliland, S. E. (2003). Growth of Probiotic and Traditional Yogurt Cultures in Milk Supplemented with Whey Protein Hydrolysate. Journal of Food Science, 68, 2090-2095.

[64] Mohammad, M. A., Molloy, A., Scott, J., \& Hussein, L. (2006). Plasma cobalamin and folate and their metabolic markers methylmalonic acid and total homocysteine among Egyptian children before and after nutritional supplementation with the probiotic bacteria Lactobacillus acidophilus in yoghurt matrix. International Journal of Food Sciences and Nutrition, 57, 470-480.

[65] Mutuş, R., Kocaba li, N., Alp, M., Acar, N., Eren, M., \& Gezen, Ş. Ş. (2006). The effect of dietary probiotic supplementation on tibial bone characteristics and strength in broilers. Poultry science, 85 , 1621-1625.

[66] Nissen, S. E., Tsunoda, T., Tuzcu, E. M., Schoenhagen, P., Cooper, C. J., Yasin, M., Eaton, G. M., Lauer, M. A., Sheldon, W. S., \& Grines, C. L. (2003). Effect of recombinant ApoA-I Milano on coronary atherosclerosis in patients with acute coronary syndromes. JAMA: The Journal of the American Medical Association, 290, 2292-2300.

[67] Noh, D., Kim, S., \& Gilliland, S. (1997). Incorporation of Cholesterol into the Cellular Membrane of Lactobacillus acidophilus ATCC 43121. Journal of dairy science, 80, 3107-3113.

[68] Ooi, L. G., \& Liong, M. T. (2010). Cholesterol-lowering effects of probiotics and prebiotics: a review of in vivo and in vitro findings. International Journal of Molecular Sciences, 11, 2499-2522.

[69] Østlie, H. M., Helland, M. H., \& Narvhus, J. A. (2003). Growth and metabolism of selected strains of probiotic bacteria in milk. International Journal of Food Microbiology, 87, 17-27.

[70] Ouwehand, A. C., Salminen, S., \& Isolauri, E. (2002). Probiotics: an overview of beneficial effects. Antonie van Leeuwenhoek, 82, 279-289.

[71] Parvez, S., Kim, H.-Y., Lee, H.-C., \& Kim, D.-S. (2006). Bile salt hydrolase and cholesterol removal effect by Bifidobacterium bifidum NRRL 1976. World Journal of Microbiology and Biotechnology, 22, 455-459.

[72] Pereira, D. I. A., \& Gibson, G. R. (2002a). Cholesterol assimilation by lactic acid bacteria and bifidobacteria isolated from the human gut. Applied and Environmental Microbiology, 68, 4689-4693.

[73] Pereira, D. I. A., \& Gibson, G. R. (2002b). Effects of consumption of probiotics and prebiotics on serum lipid levels in humans. Critical reviews in biochemistry and molecular biology, 37, 259-281. 
[74] Peres, C. M., Peres, C., Hernández-Mendoza, A., \& Malcata, F. X. (2012). Review on fermented plant materials as carriers and sources of potentially probiotic lactic acid bacteria-With an emphasis on table olives. Trends in Food Science \& Technology, 26, 31-42.

[75] Playne, M., Bennett, L., \& Smithers, G. (2003). Functional dairy foods and ingredients. Australian Journal of Dairy Technology, 58, 242-264.

[76] Richelsen, B., Kristensen, K., \& Pedersen, S. (1996). Long-term (6 months) effect of a new fermented milk product on the level of plasma lipoproteins--a placebo-controlled and double blind study. European journal of clinical nutrition, 50, 811.

[77] Sánchez, B., Ruiz, L., Gueimonde, M., Ruas-Madiedo, P., \& Margolles, A. (2012). Toward improving technological and functional properties of probiotics in foods. Trends in Food Science \& Technology, 26, 56-63

[78] Sarkar, S., \& Misra, A. K. (2001). Characteristics of dietetic yoghurt. Indian Journal of Dairy \& Biosciences, 12, 76-79.

[79] Schaafsma, G., Meuling, W. J., van Dokkum, W., \& Bouley, C. (1998). Effects of a milk product, fermented by Lactobacillus acidophilus and with fructo-oligosaccharides added, on blood lipids in male volunteers. European journal of clinical nutrition, 52, 436-440.

[80] Shah, N. P. (2000a). Probiotic bacteria: selective enumeration and survival in dairy foods. Journal of dairy science, 83, 894-907.

[81] Shah, N. P. (2000b). Effects of milk-derived bioactives: an overview. British Journal of Nutrition, 84, 3.

[82] Shah, N. P. (2004). Probiotics and prebiotics. Agro Food industry Hi Tech, 15, 13-17.

[83] Shah, N. P. (2007). Functional cultures and health benefits. International Dairy Journal, 17, 1262-1277.

[84] Shin, H. S., Park, S. Y., Lee, D. K., Kim, S. A., An, H. M., Kim, J. R., Kim, M. J., Cha, M. G., Lee, S. W., \& Kim, K. J. (2010).

Hypocholesterolemic effect of sonication-killed Bifidobacterium longum isolated from healthy adult Koreans in high cholesterol fed rats. Archives of pharmacal research, 33, 1425-1431.

[85] Srinivas, H., Prabha, R., \& Shankar, P. A. (1997). Characteristics of cultured milks, yoghurt and probiotic yoghurts prepared from pre-refrigerated milks. Journal of Food Science and Technology, 34, $162-164$.

[86] St-Onge, M. P., Farnworth, E. R., \& Jones, P. J. H. (2000). Consumption of fermented and nonfermented dairy products: effects on cholesterol concentrations and metabolism. The American Journal of Clinical Nutrition, 71, 674-681.

[87] Talwalkar, A., \& Kailasapathy, K. (2004). A Review of Oxygen Toxicity in Probiotic Yogurts: Influence on the Survival of Probiotic Bacteria and Protective Techniques. Comprehensive Reviews in Food Science and Food Safety, 3, 117-124.

[88] Talwalkar, A., Miller, C. W., Kailasapathy, K., \& Nguyen, M. H. (2004). Effect of packaging materials and dissolved oxygen on the survival of probiotic bacteria in yoghurt. International Journal of Food Science \& Technology, 39, 605-611.

[89] Tannock, G. (1999). Analysis of the intestinal microflora: a renaissance. Antonie van Leeuwenhoek, 76, 265-278.

[90] Taranto, M., Medici, M., Perdigon, G., Ruiz Holgado, A., \& Valdez, G. (1998). Evidence for Hypocholesterolemic Effect of Lactobacillus reuteri in Hypercholesterolemic Mice. Journal of dairy science, 81, 2336-2340.
[91] Theuwissen, E., \& Mensink, R. P. (2008). Water-soluble dietary fibers and cardiovascular disease. Physiology \& Behavior, 94, 285-292.

[92] Vrese, M., \& Schrezenmeir, J. (2008). Probiotics, Prebiotics, and Synbiotics. In U. Stahl, U. B. Donalies \& E. Nevoigt (Eds.), Food Biotechnology (Vol. 111, pp. 1-66): Springer Berlin Heidelberg.

[93] Walldius, G., \& Jungner, I. (2004). Apolipoprotein B and apolipoprotein A-I: risk indicators of coronary heart disease and targets for lipid-modifying therapy. Journal of Internal Medicine, 255, 188-205.

[94] Xiao, J. Z., Kondo, S., Takahashi, N., Miyaji, K., Oshida, K., Hiramatsu, A., Iwatsuki, K., Kokubo, S., \& Hosono, A. (2003). Effects of milk products fermented by Bifidobacterium longum on blood lipids in rats and healthy adult male volunteers. Journal of dairy science, $86,2452-2461$.

[95] Yamamah, G. A. N., Mehana, N., Salem, M., Abou-Zekri, M., Khashaba, O., \& El-fiki, E. (2005). The role of Bifidobacterium bifidum and Lactobacillus acidophilus as probiotics in controlling infantile watery diarrhea. Egyptian Medical Journal, 4, 29-34.

[96] Zhong, Y., Huang, C. Y., He, T., \& Harmsen, H. M. (2006). Effect of probiotics and yogurt on colonic microflora in subjects with lactose intolerance. Journal of Hygiene Research, 35, 587-591.

\section{AUTHOR BIOGRAPHY}

Amin Ismail Department of Nutrition and Dietetics, Faculty of Medicine and Health Sciences, Laboratory of Halal Science Research, Halal Products Research Institutes,

Sadeq Hasan Al-Sheraji Department of Nutrition and Dietetics, Faculty of Medicine and Health Sciences, Universiti Putra Malaysia, 43400 UPM Serdang, Selangor, Malaysia.Department of Food Science, Faculty of Agriculture, Ibb University, Ibb, Yemen.

Azrina Azlan Department of Nutrition and Dietetics, Faculty of Medicine and Health Sciences, Universiti Putra Malaysia, 43400 UPM Serdang, Selangor, Malaysia. 